\title{
Inter-Organizational Knowledge Conversion and Innovative Capacity in Cooperative Networks
}

\author{
Patrícia Trindade Caldas', Gesinaldo Ataíde Cândido²
}

\begin{abstract}
In the current business and management environments, organizations are challenged to search for new ways of working focused on findings and practical innovation. In this sense, knowledge management constitutes a tool to support the practices of innovation, which are facilitated by the existence of physical, virtual or mental spaces, called Ba's, where knowledge can be better used. The objective of this paper is to analyze the dynamics of inter-organizational knowledge conversion into existing $\mathrm{Ba}$ spaces in a cooperative network. The data analysis was performed from the triangulation of primary and secondary data and from the non-participant observation, within specific variables. The results point that the network displays an unfavorable configuration regarding the favorable characteristics to dynamics of knowledge conversion, which influences negatively its performance, especially the intensity and quality of information.
\end{abstract}

Keywords: management; knowledge; innovation; competitiveness.

Federal University of Campina Grande. 'R. Manoel Elias de Araujo, 599, Ap. 102 - Jardim Tavares, Campina Grande-PB, Brazil. CEP: 58402022. Phone: (55) 838803 1832. E-mail:ptcaldas@yahoo.com.br

2R.Aprígio Velozo, 882 - Universitário. Campina Grande-PB, Brazil. CEP: 58429-900. E-mail: gacandido@uol.com.br 


\section{Introduction}

In contemporary society of knowledge, the enduring competitive advantage is achieved, among other factors, by acquiring new knowledge and skills through learning intensification of persons and organizations. Therefore, the use of knowledge bound for to seek and practice the innovation will contribute more positively to competitiveness, since this feature has specific attributes difficult to be imitated, adding economic, social and competitive values for organizations.

Knowledge management is a complex activity because it is an intangible, dynamic and intrinsic asset to human beings, but it is essential for the survival and development of organizations. Knowledge Management (KM) arises precisely in order to support a more effective use of knowledge by organizations from the promotion and encouragement of a set of processes related to the creation, use and dissemination of knowledge in the organization (Davenport and Prusak, 1998).

Among the studies of the KM, we highlight the work of Nonaka and Takeuchi (1997) that points out the creation of knowledge through the process of converting knowledge $\mathrm{SECl}$ (Socialization - Outsourcing - Combination - Internalization) from the interaction between tacit and explicit knowledge.

However, for this SECl knowledge conversion process occurs effectively is necessary the existence of an appropriate context, that Nonaka and Konno (1998) called Ba - a physi$\mathrm{cal}$, mental or virtual space within knowledge is generated, shared and used. Such means should be composed by facilitating elements related to culture, technology, organizational structure, management, style, communication, among others. Besides these factors, aspects related to arrangements and social groupings, such as trust, collaboration, cooperation and mutual aid also influence the mode and the spaces in which knowledge is created and disseminated.

Thus, this study assumes that the more features that facilitate the sharing of knowledge exist and are optimized, the greater the existence of Ba's spaces, and thus better the dynamics of conversion of existing knowledge, corroborating to the organizational capacity for learning and use of intellectual resource in supporting the differentiation and competitive advantage.

In this sense, the study of new patterns of international business relationships, such as business networks can contribute to generate new and facilitating factors influencing the conversion of knowledge and the existence of organizational Ba's. Through cooperative practices, rooted in mechanisms of integration, coordination and dissemination of knowl- edge, cooperation networks present opportunities to exchange ideas and information, collaborating to produce new knowledge and innovations, and enabling broader analysis of knowledge which transcends the boundaries of the organization.

Based on these considerations, the aim of this paper is to analyze the dynamics of inter-organizational knowledge conversion into physical, virtual and mental spaces existing in a cooperative network of manufacturing sector in the city of Campina Grande, Paraíba State. Therefore, the work of Balestrin, Vargas and Fayard (2005), Terra (200I), Hoffmann et al. (2004) and Cândido (200I) were used as theoretical and methodological support, in which factors that influence the dynamics of inter-organizational conversion were selected, i.e., the process of creating and sharing knowledge at the individual level for inter-organizational level, considering the multifaceted character of knowledge management applied to new organizational architectures such as cooperation networks.

In terms of methodology, the study can be characterized as exploratory and descriptive, using techniques such as literature review, document analysis, no-participant observation and obtaining primary data through semi-structured interviews with social actors directly linked to Natural Fashion network.

Natural Fashion network comprises a group of small businessmen in the manufacturing sector responsible for the production of clothing and accessories. This network was created with the aim of participating in the revitalization program of cotton production in Paraíba State. Using naturally colored cotton as the main raw material, the Natural Fashion network employs the concept of natural, social and environmentally friendly product to deal with market difficulties faced by small businesses in the manufacturing sector in Paraíba State.

In addition this introduction, the article explores the theoretical concepts and approaches to Knowledge Management; Inter-organizational Networks and Inter-Organizational Knowledge Expansion. Then, the procedures, the characterization of the studied network, the results and discussion, final conclusions and recommendations for new studies and researches are presented.

\section{Theoretical Framework}

\section{Knowledge Management (KM)}

Knowledge management has been systematically used as a mechanism to contribute in optimizing the use of various types of resources and the viability of business strategies from the improvements in information flows. 
The literature includes a large array of definitions about this construct, but in general, knowledge management has the purpose to spread the value added information throughout the organization in order to raise the organizational performance (Paiva, 2005).

For Leonard-Barton (1998), organizations need to be well-informed and to learn transforming information into knowledge, since the strategic management of knowledge determines the ability of companies to adapt, compete and survive.

Among the approaches of studies of $\mathrm{KM}$, the focus on knowledge creation arouses the attention of many researchers, as Nonaka and Takeuchi (1997), Schreiber et al. (2000), and Balestrin, Vargas and Fayard (2005), which recognize the ability to create and use knowledge as an important source of sustainable competitive advantage for organizations. In the following, Nonaka and Tackeuchi (1997) and Nonaka and Konno (1998) approaches were used as the basis of this research.

\section{The Creation of Organizational Knowledge According to Nonaka and Takeuchi (1997) and Nonaka and Konno (1998) Perspectives}

According to Nonaka and Takeuchi (1997), the main reason for the success of the company is its competency in building organizational knowledge, which is obtained when social processes are developed and able to create new knowledge by converting tacit knowledge into explicit knowledge (through an information process), and when the synergy between these two types of knowledge is recognized.

Tacit knowledge is understood as what people know implicitly, subjective insights. Generally, this knowledge results from personal experiences, as well as it is strongly related to the action, procedures, routines, ideas, values and emotions. On the other hand, explicit knowledge is defined as one that can be articulated, formalized and easily transferred and disseminated between people. It is expressed in a formal and systematic way, being shared in the form of data, scientific formulas and specifications.

According to the authors, the passage of tacit knowledge to explicit, and vice versa, is based on continuous and dynamic social interaction, being a spiral process. In this sense, the authors developed a model which presents two dimensions, exhibited in Figure I.

It is observed that amplification of knowledge occurs in two extensions: (I) the epistemological dimension, which converts tacit knowledge into explicit knowledge from a spiral of knowledge consisting four phases of the SECl model - socialization, externalization combination and internalization; and (2) the ontological dimension which transfers the individual knowledge for the group, which in turn passes into the organization and other organizations.

In this perspective, Nonaka and Konno (1998) argue that for knowledge creation occurs, the organization needs to create the right conditions and appropriate context that provides facilities for group activities and allows the creation and accumulation of knowledge at the individual level. Later, these contexts were named $\mathrm{Ba}$ and they were defined as a physical, mental or virtual spaces, within knowledge is generated, shared and used.

In view of the spiral of knowledge creation of Nonaka and Takeuchi (1997), the authors relate a Ba for each phase of the $\mathrm{SECl}$ process of knowledge conversion, presenting four types of Ba:

\section{Where:}

Originating $\mathrm{Ba}$ : is the space where the stage of knowledge socialization occurs, with the conversion of tacit knowledge to tacit knowledge through shared experiences. This, it is

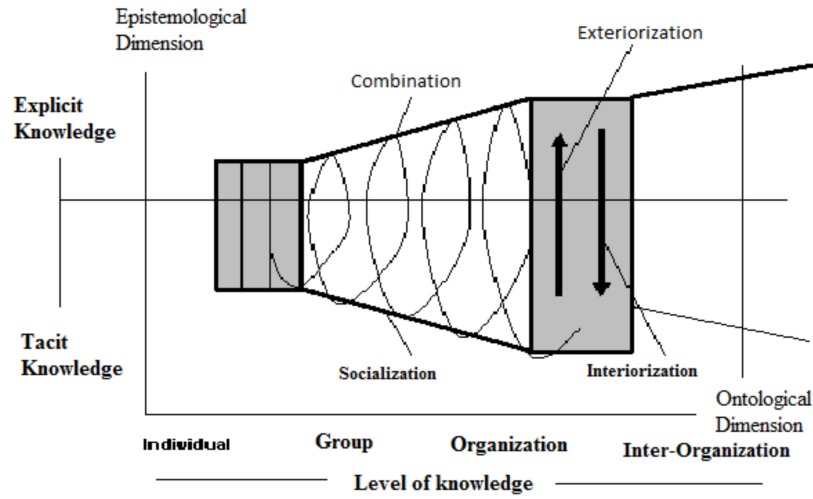

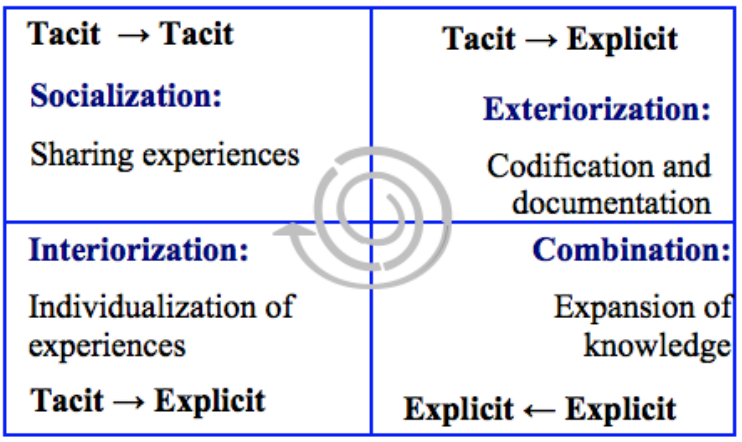

Figure I - Spiral of organizational knowledge creation Source: Nonaka and Takeuchi (1997)

ISSN: 07 I8-2724. (http://www.jotmi.org)

Journal of Technology Management \& Innovation (c) Universidad Alberto Hurtado, Facultad de Economía y Negocios. 


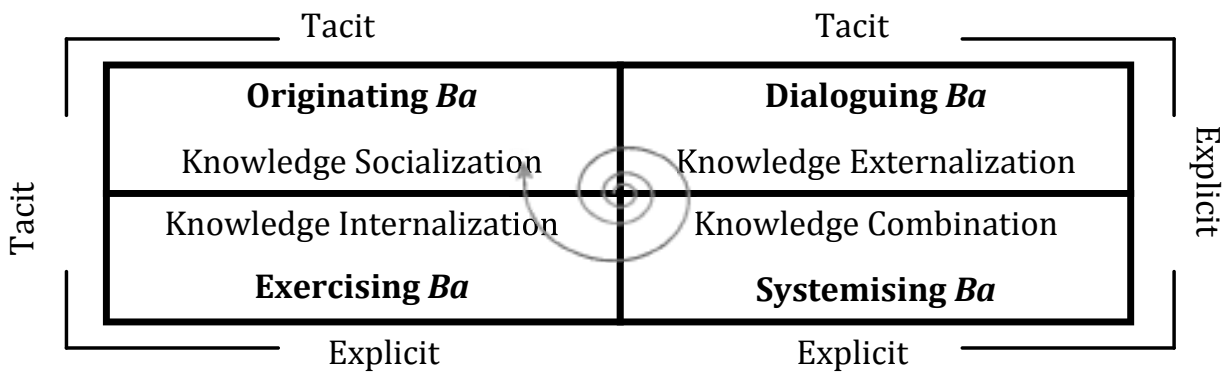

Figure 2 - The $\mathrm{SECl}$ process and types of $\mathrm{Ba}$

Source:Adapted from Nonaka et al. (2002)

characterized by individual and direct interactions (face-toface), where individuals share feelings, emotions, experiences and mental models. Therefore, there must be factors such as love, trust and commitment.

Dialoguing $\mathrm{Ba}$ : It is the space related to the manifestation of knowledge, resulting in the conversion of tacit knowledge to explicit knowledge through more explicit, structured and conscious actions. Here, dialogue is the main transferring channel, where there are collective interactions in a direct situation, face-to-face. This is a place where individual mental models and skills are shared, converted into common terms and articulated as concepts (Nonaka et al., 2002).

Systematizing Ba: It is the space where the combination of knowledge occurs (conversion of explicit knowledge into explicit knowledge) via physical and/or virtual communication. Therefore, it is characterized by collective and virtual interactions, aiming to create new sets of explicit knowledge that can be understandably transmitted later. Information Technologies are very supportive to this step dynamics.

Exercising $\mathrm{Ba}$ : It is the space where the internalization of knowledge occurs by converting tacit knowledge into explicit knowledge, through the incorporation of explicit knowledge by human capital, opening space for generating new concepts and working practices. This internalization is closely related to learning. Therefore, there are individual, virtual and/or mental interactions. This Ba summarizes the processes of reflection and transcendence through action, while $\mathrm{Ba}$ dialogue achieves this synthesis through thought (Nonaka et al., 2002).

From these considerations, it is inferred that $\mathrm{Ba}$ is closely related to the interactions between individuals, dealing with the emergence of specific intangible aspects such as trust, love, commitment and cooperation. These aspects tend to exist in enterprise networks, practices generally held by small businesses to support the strong competition of the global market.

\section{Business Networks and Expansion of Inter-Organizational Knowledge}

Networks are collections of individuals and/or organizations that are directly or indirectly linked and involved through a social relationship, which should be engaged and conduct actions that reflect the exchange of objects of value and meaning through interaction (Marcon and Moinet, 2000).

The formation in network provides greater flow of information and shared knowledge that stimulates learning and dissemination of information, turning ideas into actions quickly (Hoffmann et al., 2004). Furthermore, the feasibility of joint actions with partner companies favors the creation and conversion of knowledge, generating intellectual capital and innovation capacity.

Networks can be configured as flexible networks, clusters, cooperation networks, local productive arrangements (APL's), among others. But regardless of the type of network, it must provide some basic principles such as interaction, sharing and integration to allow benefits between firms.

Thus, through these evidences it is clear that the network environment stimulates the conversion of knowledge dynamics because they are prone to adopt enabling properties, namely: cooperation, trust and social interaction, which collaborate to create and exchange ideas, information and knowledge. Moreover, the study of new patterns of relationships such as networks enables a more extended knowledge outside the physical boundaries of a company.

\section{Methodological Procedures}

This research can be characterized as exploratory descriptive and it was carried out as a case study at Natural Fashion network, which includes 22 stakeholders. From this total, fifteen (I5) stakeholders - or $65.22 \%$ of the universe - were consulted, which allowed a positive representation for a reli-

ISSN: 07 I8-2724. (http://www.jotmi.org)

Journal of Technology Management \& Innovation (c) Universidad Alberto Hurtado, Facultad de Economía y Negocios. 
able analysis of quantitative and qualitative variables. It was used non-probability sampling based on the criteria of accessibility.

Besides literature review, other techniques were used for data collection such as documentary analysis, non-participant observation and semi-structured interviews based on a questionnaire with social actors which are directly or indirectly linked to the network.

The formation of the research variables was based on the work of Balestrin, Vargas and Fayard (2005), but it was necessary to add other variables existing in literature in order to present aspects related to $\mathrm{SECl}$ process conversion of Nonaka and Tackeuchi (1997). Therefore, other variables were found in the models of Terra (200I), Hoffmann et al (2004) and Cândido (200I), as it one can see on Table I:

In the data analysis was done a triangulation of different sources of data on the correlation between the primary data (collected from interviews) and secondary data (obtained through the literature review and document analysis and non-participant observation).

\section{Presentation and Results Analysis}

\section{Characterization of Environment Research}

Natural Fashion network was founded on April 04, 2000 with the objective to strengthen the textile and apparel companies in Campina Grande to face the competition in the external market. From the opportunity created by the research about naturally colored cotton, these companies could enable the network to produce a clothing product that presents ecological and social benefits.

Currently, naturally colored cotton comes in beige, brown and green without suffering any genetic alteration, whose fiber is the longest and toughest in the world. To be born colored, cotton dispenses dyes and colorings, thereby avoiding contamination of nature. Colored cotton also provide better remuneration to the whole production chain, from the farmer, seamstress, craftsman, small businessmen by making items with high quality of social standards.

By the production of social and eco-friendly goods with great potential for sales abroad, the network was expanded, requiring the structuring of relations for the entry of new partners and the increasing commercialization of the products were feasible. For this purpose, partnerships with various support institutions in the region were sought.

Natural Fashion network offers to the market the quality of a handmade product ecologically and socially correct, using the concept of family farming, artisanal labor, associations of mothers, and residents in the suburbs of Campina Grande. The collection developed with naturally colored cotton makes a reinterpretation of northeastern culture linked to international fashion trends.

\section{Dynamics of Inter-organizational Knowledge Conversion in Natural Fashion Network}

Data analysis was performed by the research variables shown in Table I, referring to the dimensions "characterization of cooperative network" and "Ba and knowledge creation", to identify the existing Ba spaces. The variables of the dimensions were analyzed as a favorable or not favorable feature to the dynamics of inter-organizational knowledge according to the qualitative evidence that were found. Below is the discrimination of the results:

\section{Geographical proximity (dispersed or agglomerated network)}

It was observed that $80 \%$ of respondents are located in Campina Grande, which characterizes the network as Agglomerated.Another factor that characterizes the agglomeration network is the social relationships among participants that go beyond the commercial relation only. Moreover, business institutions support this network through constant consulting.

Directionality of relationships (vertical or horizontal network)

It is observed that there is the predominance of horizontal directivity, since the participating companies operate in the same stage of the production chain, which is the beneficiation of textile industry and marketing performing the complete individual production of a given product. This classification allows exchanges and common benefits, stimulating the existing cooperation character and giving equal conditions of aggregation value to the activities. In this sense, the dynamics of inter-organizational knowledge conversion is judged as favorable.

\section{Objectives, Vision and Strategy}

With regard to the strategic guidelines adopted by the network regarding to the goals, vision and strategy, it was observed that there is a communication of strategic information (those already defined). In fact, it was noticed that the more general strategic information (such as macros goals) were well formulated and communicated at the time of the formation of the network. However, there is not the same definition and clarity about the more specific information of short term service (specific objectives), both for lack of

ISSN: 07 I8-2724. (http://www.jotmi.org) 
motivation of members, as the lack of proper governance, which can harm the network by causing disorientation to participants in relation to actions that should be taken in the future. In general, this variable presented a positive score for having strategic guidelines updated with the contemporary context. On the other hand it is necessary to correct specific aspects to ensure this assessment for a longer period of time.

Formalization of relationships (formal or informal)

It is verified that the network was initially established as mutual interests for cooperation supported by trust between the founders. After some time, it was formalized as a cooperative, which legally must be based on well structured formal contracts. Therefore, this network can be classified, at its current stage, as the formal contractual basis. This situation enables inferring a positive rating for this variable, because due to formalized relationships, the network has greater control and assurance in relation to opportunistic behavior.
Degree of power hierarchy (orbital versus no orbital; hierarchy versus heterarchy, centralized versus participative management)

The network is configured as orbital, which presents a center that is responsible for coordinating the network (the board), which directs the other members. Despite this classification, it is observed that all members have equal rights to participate in decision making. Although the management structure is flexible and focused on open participation, it is not always a democratic process due to the lack of motivation or disinterest on the part of members, or sometimes shyness or lack of qualification to expose reasoned and correct ideas, among other reasons. This fact results in a different perception among participants regarding their individual influence on the network, which reflects a negative aspect that might harm future relationships, cooperation and hinder the progress of the network as a whole. Because social networking is the basis for the creation and transferring of knowledge, it is necessary to work for such discrepancies avoid harming the dynamics of knowledge network. In con-

\begin{tabular}{|c|c|c|}
\hline Dimensions & $\begin{array}{l}\text { Objectives of the } \\
\text { Research }\end{array}$ & Research Variables \\
\hline $\begin{array}{l}\text { Caracte- } \\
\text { rization of } \\
\text { Cooperative } \\
\text { Network }\end{array}$ & $\begin{array}{l}\text { Identify the char- } \\
\text { acteristics and } \\
\text { factors that influ- } \\
\text { ence the dynamics } \\
\text { of knowledge } \\
\text { conversion of } \\
\text { Natural Fashion } \\
\text { network }\end{array}$ & $\begin{array}{ll}- & \text { Geographical proximity; } \\
- & \text { Directionality of relationships *; } \\
- & \text { Objectives,Vision and Strategy *; } \\
- & \text { Formalization of relationships; } \\
- & \text { Degree of power hierarchy } * ; \\
- & \text { Instruments of coordination and evaluation; } \\
- & \text { Level of cooperation/competition; } \\
- & \text { Physical infrastructure focused on collective interaction } * * ; \\
- & \text { Infrastructure of TIC and SI focused on collective interaction } * * ; \\
- & \text { Human structure } * * ; \\
- & \text { Culture existing in the interorganizational environment } * * ; \\
- & \text { Trust between agents } * ; \\
- & \text { Opportunism existing in relation to knowledge } * * ; \\
- & \text { Simetry/assimetry of knowledge } * * * ; \\
- & \text { Intern interaction } * * ; \\
- & \text { Extern interaction } * *\end{array}$ \\
\hline $\begin{array}{l}\text { Ba and } \\
\text { creation of } \\
\text { knowledge }\end{array}$ & $\begin{array}{l}\text { Identifying } \mathrm{Ba} \\
\text { spaces existing in } \\
\text { the network }\end{array}$ & $\begin{array}{l}\text { Types and quantities of Ba dedicated to knowledge socialization; } \\
\text { Types and quantities of Ba dedicated to knowledge externalization; } \\
\text { Types and quantities of Ba dedicated to knowledge combination; } \\
\text { Types and quantities of Ba dedicated to knowledge internalization; } \\
\text { Results of dynamics of knowledge creation. }\end{array}$ \\
\hline
\end{tabular}

Table I - Research variables

Source:Adapted from Balestrin,Vargas and Fayard (2005)

Where: $(*)$ Adapted Variables: the definition of this variable was amplified based on the perception of the other researched authors, namely:Terra (200I), Cândido (200I) and/or Hoffmann et al (2004);

(**) Added Variables: these variables were added to the model based on the perceptions of the investigated stakeholders; (***) Reorganized variables: these variables were rearranged from dimension "Ba and knowledge creation" (the original model) for "Cooperation Networks".

ISSN: 07 I8-2724. (http://www.jotmi.org)

Journal of Technology Management \& Innovation (c) Universidad Alberto Hurtado, Facultad de Economía y Negocios. 
clusion, it is believed that the network presents this variable in a positive setting, but with warning.

Coordination and evaluation tools (management, feedback and control)

None of these mechanisms was perceived in the network, resulting in unfavorable rating for this variable. It is observed that governance is given by the Board that outlines the goals and direction of the network, although it does require that all abide by the final decision. It was not clear from the collected data, whether sales history and/or information from companies are used to base this approach in the network.

\section{Level of cooperation/competition among network participants}

It is noticed that despite cooperation being predominant over competition, cooperation should be worked on and practiced with greater intensity by the network members. It was observed that the respondents understand the importance of this aspect for the success and strengthening of the network, but cooperation is performed on more operational activities such as joint purchases and sharing of sales orders. It is necessary to extend cooperation and information resources, mainly to strengthen the capacity for learning and innovation the network as a whole. Thus, this variable was judged to be unfavorable to the dissemination of knowledge.

Physical infrastructure focused on collective interaction (such as meeting rooms, reading areas, $R \& D$ laboratories, among others):

This is an unfavorable variable and it is visibly realized by the cooperators, although they had already taken decisions to improve it. Currently, the network headquarters has hardly any space for social interaction of cooperative members: about $80 \%$ of the network area is filled with merchandise inventories and work environments. To exchange knowledge and social interactions there are only two small rooms, which are also workplaces. It has been voted in assembly to enlarge the area to include the physical needs displayed in the survey.

Infrastructure of Information and Technology Information (ICT) and Information System (IS) focused on collective interaction

According to most respondents ( $73 \%$ ), the network presents technology infrastructure although it is not used effectively to support the information necessary to all participants. In fact, the network presents computerized workstations and computational network utilization (internal and external) aiming virtual communications between members and other agents that use such technologies. Despite the availability and requirement by the Board for the utilization of compu- tational network and ICT as a communication channel, many participants still do not use it due to cultural reasons, lack of investment or lack of training, as presented below.

\section{Human structure}

Although most owners have graduation and understand the need of being in constant process of adaptation and qualification to accompany the external demands, most of them dealing in practice with manual processes and obsolete machinery and, therefore, they do not perceive their learning capacity either their ability of innovating. Their employees do not have adequate qualifications or receive incentive to handle and enjoy emerging technologies, which could come from incentive programs as a basic award and recognition. Consequently, they do not help adequately the innovativeness of companies and network as a whole.

Another aspect found related to human structure refers to the incentive of the formation of cross-functional teams for social interaction, exchange of knowledge and experiences, and greater capacity for innovation consequently.Among the speeches, three groups that can be considered as functional teams were detected: $(I)$ the design group, which is still in process of formation and consists of the main companies that create and develop collections, (2) the GEOR - Oriented Management for Results, a group that is supported by SEBRAE (The Brazilian Service of Support for Micro and Small Enterprise) and is formed by some clothing companies to conduct planning and, (3) the strategic planning. The presence of such teams, although they contemplate only a few people, is favorable to the dynamics of knowledge in the network because they are a source of innovation of products and processes aligned with market trends. However, more initiative and time availability to cooperate on the part of participants and greater encouragement and motivation on the part of network engineers are necessary.

\section{Culture existing in the inter-organizational environment}

It is observed that $80 \%$ of respondents agree that the existing culture and organizational environment encourages the adoption of values that promote the intellectual capital, but there are barriers due to individual local culture. On the other hand, favors a cooperative stimulation of values around cooperation and mutual aid. These values are beneficial to promoting the growth of intellectual capital network they help to encourage exchange and collaboration among peers. Despite this variable to be considered favorable, there must be a greater motivation around innovation and learning, experimentation, change so there optimization of all areas of the company for the long term. This is a difficult aspect to be developed and time required to be effective. 
On the other hand, a cooperative promotes the stimulation of values around the cooperation and mutual help. These values are beneficial to promote the increase of intellectual capital in the network being helpful to encourage exchange and collaboration among peers. Despite this variable is considered favorable, it is necessary a greater motivation for innovation and learning, experimentation, and change in order to optimize all areas of the company in long term. This is a difficult aspect to be developed and it requires time to be effective.

\section{Trust in information sharing}

It is perceived that in a broader perspective trust exists between the cooperative members of Natural Fashion network mainly due to the training process, which was based on previous friendships. It was also observed the presence of transparency and honesty among the participants that are influencing factors on existing trust. These features facilitate the relationship between the partners, as well as maintaining strategic and enduring alliances between them.

Opportunism of some companies in relation to the existing knowledge on the network

Although the majority (80\%) have responded that disagrees that there are companies in the network that receive information or unique benefits, it is clear from the reports that these facts did not happen for reasons of opportunism, but because of the greater interest of some cooperative with the network. Opportunism happens when some participants are benefited individually by holding proprietary information or differential treatment of others, creating individual advantage rather than the collective. Such behaviors can cause jealousy and discussions, affecting trust and cooperation among members, and as a consequence, affecting the process of creation and transferring of knowledge. As the perceived differentiation generates no distinctions or individual advantage, according to respondents, the network also has no problems with opportunism.

\section{Symmetry/asymmetry of knowledge}

There is agreement on the part of the majority (93.33\%) that the participants use different information. This differentiation is caused in more specific terms concerning the different production lines, where different information are used, but not so asymmetrical since they are similar processes Regarding the cooperative management information, these are more symmetrical.Also according to the majority of respondents (73.33\%), everyone has something to add, because people are different from each other, with different thoughts and knowledge according to their own experiences. Nevertheless, in the practice, people give themselves in a way and frequency differentiated towards the collective. They are more symmetrical.Also according to the majority of respondents (73.33\%), everyone has something to add, because people are different from each other, with different thoughts and knowledge according to their living experiences. Although such a finding, in practice people give themselves often and differentiated towards the collective.

\section{Intern interaction}

Regarding the internal interaction, it is observed that the synergy and interaction between the companies participating in the network directly affect exchanges of knowledge between them. Therefore, the majority $(80 \%)$ agree that there is a relationship and exchange of knowledge, although such synergies have to be effected more frequently and with a greater focus on knowledge exchange. It is important that the relationships of the participants of a network are accessible and frequent, since it is directly involved in the creation and transferring of knowledge. It is necessary to promote more frequent meetings and with other focuses than deciding the strategic actions or operational network, but with intentions of creating and developing specific concepts that produce greater value for people, for businesses and for the network as a whole.

\section{Extern interaction}

Social interaction with other external partners to the network is also essential. However, about $67 \%$ of respondents disagree with an effective relationship between the participants and other external agents, since such contact is done more often by the cooperative, in the figure of the president or director/financial manager. For these respondents, the cooperative has the responsibility to get customers and suppliers, to maintain contact with the institutions and support agency, and to conduct marketing and business. The responsibility of contacting with external agents is fragile. It should be observed how this centralization is healthy and sustainable for members and for the network, because these contacts are important sources of information on trends and market opportunities. It was noticed that some participants are "anchoring" on the network board and settling, without having concrete initiatives to monitor the market or innovation.

According to the exposed qualitative analysis, it was formulated the Table 2 in the following with the qualitative assessment of research variables:

From the obtained considerations, the Natural Fashion network presents an intermediate configuration, but it is not a satisfactory result considering the initial condition of study that cooperation networks should provide the minimum 
characteristics that influence the process of knowledge conversion in an unfavorable position.

Due to the interdependence character of research variables, in which one variable can influence another in a positive or negative aspect, it is necessary to recognize the unfavorable variables to the network and make the adjustments to its dynamics of inter-conversion of knowledge. If this is not done in a short time, there may be negative evolution of the network in terms of relationships focused on the creation and transferring of knowledge, which in turn will adversely affect a number of other important aspects of network support in market such as innovation capacity and competitiveness of the network itself.

It was also observed that the network presents variables difficult to be worked in favorable conditions, as for example the confidence, that is an intangible character constructed over time, but that can be easily negatively influenced by unfavorable variables.

The network also has other positive variables that currently bring competitive advantage, but if they are not worked sustainably, they can be stabilized by the market. This is the case of the strategy with a focus on nature and on social and environmentally friendly products. It is already clear that the colored cotton is not the raw material for exclusive products of Natural Fashion and several competitors have emerged and supported in this historic brand to produce and sell similar products in the same line of work. A greater planning, setting goals, challenging and innovative actions are required.

Other factors, however, were considered unfavorable and urgently needed to be improved, namely: cooperation and capacity building, although the other variables considered unfavorable for dynamic inter-conversion of knowledge in the network should not be forgotten.

Regarding the issue of cooperation, it should not be understood only as an opening to return and exchange benefits, materials, equipment, information and knowledge. This variable has a broader meaning, involving individual donation on behalf of the collective, action and initiatives taken in addition to the availability of time to collectively seek skills, capabilities and competitive advantages to promote development both individually and collective. If all participants are waiting for actions arising only from the coordination of the network, they will not be donating individually to solve common problems or to search optimization of processes, products and capabilities, and therefore, they are not cooperating to the network. Cooperation is a variable that greatly influences the other variables and needs to be optimized with urgency.

The training, in turn, influences the degree of contribution that each one can donate to the network, since it will increase the knowledge and understanding of each on related

\begin{tabular}{|l|l|l|}
\hline Influential characteristics & Evaluation & Percentage \\
\hline Geographical proximity & + & $\begin{array}{l}\text { Favorable } \\
50 \%\end{array}$ \\
\hline Directionality of relationships & + & $\begin{array}{l}\text { Unfavorable } \\
50 \%\end{array}$ \\
\hline Objectives,Vision and Strategy & + & \\
\hline Formalization of relationships & + & \\
\hline Degree of power hierarchy & + & \\
\hline Instruments of coordination and evaluation & - & \\
\hline Level of cooperation / competition & - \\
\hline Physical infrastructure focused on collective interaction & - \\
\hline Infrastructure of TIC and Sl focused on collective interaction & - \\
\hline Human structure & - \\
\hline Culture existing in the interorganizational environment & + \\
\hline Trust between agents & + & \\
\hline Opportunism existing in relation to knowledge & + \\
\hline Simetry/assimetry of knowledge & - & \\
\hline Intern interaction & - & \\
\hline Extern interaction & - & \\
\hline
\end{tabular}

Table 2 - Evaluation of the characteristics that influence the process of creation and transfer of knowledge. Source: Empirical evidences of the research

ISSN: 07 I8-2724. (http://www.jotmi.org)

Journal of Technology Management \& Innovation (c) Universidad Alberto Hurtado, Facultad de Economía y Negocios. 
to issues about the production, management and commercialization of Natural Fashion. Such knowledge and understanding applied, socialized, combined with the others and internalized in physical, virtual or mental spaces generate new concepts, ideas, knowledge and positive relationships for innovation and competitiveness of the network.

Based on the above, it is necessary that the Natural Fashion network has a systemic view of what it is, recognizing their properties (both positive and negative) and their inter-relationships, promoting and leveraging Ba spaces of creation and conversion of knowledge, seeking continuous improvement, encouraging learning to improve its ability to bring innovation to favorable returns and benefits to support business in the competitive market.

Therefore, changes in thinking and internal attitudes of enterprises and managers are also required to make them realize the contributions and benefits of collective action at all levels and aspects and, thus achieving the common goal of internationalization more effectively.

Although half of the variables have been assessed negatively and they do not occur so frequently or appropriate in most cases, this condition still potentiated physical, virtual and mental spaces, which are shown in Figure 3 below:

In assessing the different types of $\mathrm{Ba}$ present on Natural Fashion network, it is observed a context for interactions, where there is exchange of all types of knowledge, from operational, administrative, commercial, strategic, social, and others.

Despite the intermediate configuration is not favorable to a satisfactory result for the dynamics of knowledge conver- sion, it was still found varied spaces and moments of synergy, which greater frequency of these participants and the specification of topics to be focused on should be encouraged. Such spaces and features represent knowledge assets which certainly provide competitive advantages to participants to small and medium enterprises (SME's) that work individually. However, many considerations need to be revised. The intention and participation in meetings with focus only and exclusively for the exchange of knowledge is one of the heard complaints and that directly influences the conversion process of inter-organizational network. Issues related to cooperation, trust, human structure, physical infrastructure, organizational culture, internal and external interaction, among others, directly influence such synergies, which should be enhanced, especially in order to socialize, externalize, combine and internalize knowledge.

In general, businessmen and other participants understand the importance of all analyzed aspects, but they need to take a proactive position to better exploit the assets and the generated spaces in order to effectively bring favorable returns to growth and competitiveness for the network as well as to the participants individually.

\section{Final Considerations}

Although the configuration concerning the influential characteristics in creating and sharing inter-organizational knowledge need for improvement, it was found some types of $\mathrm{Ba}$ that works as strategic communities of knowledge in Natural Fashion network. These spaces, as it was demonstrated in the analysis of results, facilitate the process of creating and transferring knowledge by enabling positive and constructive interactions between explicit and tacit knowledge of individuals. Also, spaces are unlikely to be found if the participants were working individually.

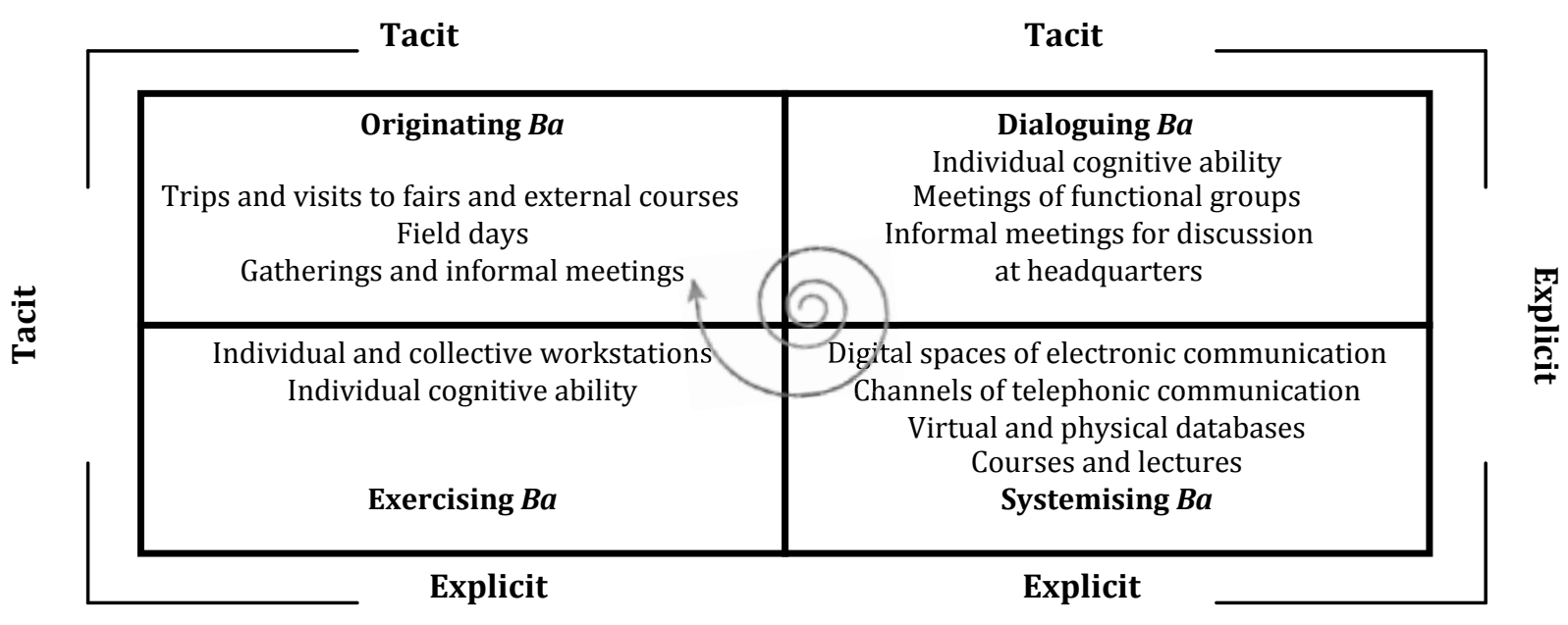

Figure 3 - Classification of different types of $\mathrm{Ba}$ in Natural Fashion network Source: Empirical evidences of research

ISSN: 07I 8-2724. (http://www.jotmi.org)

Journal of Technology Management \& Innovation (c) Universidad Alberto Hurtado, Facultad de Economía y Negocios. 
However, specifically in the network in question, this relationship needs to be strengthened and better targeted. Thus, the involved people and companies convert individual knowledge to inter-organizational level and such conversion actually bring significant returns to network development.

Therefore, some adjustments regarding the practices of cooperation and human structure are required most urgently, since they negatively influence other variables. Such lack of cooperation, collaboration, and education leveling are hindering the exchange of experience and knowledge necessary to develop the network as a whole.

The other features that were negatively evaluated also need to be addressed with the intention to provide adequate benefits and collective advantages: the goals need to be better defined and communicated, particularly the short term ones to lead to a greater focus on individual support of the community; the governance must be based on direct and more appropriate management sources; the physical infrastructure must provide effective spaces targeted for social interaction to avoid that the externalized properties are lost or be developed; and the internal and external interactions need to be further encouraged and properly optimized with the aim of exchanging knowledge.

Regarding the favorable characteristics, they also deserve attention in order that they are not negatively influenced by variables that were evaluated as unfavorable and, thus, continue adding value to the network.

Regarding the recommendations of the research, it is suggested that the variables included in this work be applied in other types of networks, such as Local Productive Arrangements (APLs), or in other economic sectors. Additionally, other methods of evaluation of the variables of investigation can be used. These can still be amplified from other perceptions found in the literature or applied in other studies. At the end of this research, for example, it can be noticed that the "availability of time for each participant to the collective" can be investigated by further work. This variable was influential on several occasions in the obtained analyzes related to the variable of cooperation, being of fundamental importance for a greater collective development. Each participant forms a conjunction with its participation, contribution and donation and the more dynamic and cooperated is this conjunction, the greater are the chances of experiencing information exchange and thus the greater the capacity to learn, innovate and be differentiated against the competitive business market.

\section{References}

BALESTRIN, A.;Vargas, L. M.; Fayard, P. (2005). Ampliação Interorganizacional Do Conhecimento: o caso das redes de cooperação. REAd - Revista Eletrônica de Administração. I I (43), I -25.

CÂNDIDO, G. A. (200I). Fatores Críticos de Sucesso no Processo de Formação, Desenvolvimento e Manutenção de Redes Interempresariais do tipo Agrupamento Industrial entre Pequenas e Médias Empresas: um estudo comparativo de experiências brasileiras. UFSC-PPGEP, Florianópolis.

DAVENPORT, T. H.; PRUSAK, L. (1998). Conhecimento empresarial. Campus, Rio de Janeiro.

HOFFMANN, V. E.; Molina-Morales, F. X.; Martinez-Fernandez, M.T. (2004). Redes de Empresas: Uma proposta de tipologia para sua Classificação. ENAMPAD, (28).

LEONARD-BARTON, D.(1998). Nascentes do saber: criando e sustentando as fontes de inovação. Editora Fundação Getúlio Vargas, Rio de Janeiro.

MARCON, M.; Moinet, N. (2000). La stratégie-réseau. Éditions Zéro Heure, Paris.

NONAKA, I.; Konno, N. (1998). The Concept of "Ba": Building a Foundation for Knowledge Creation. California Management Review. 40 (3), 40-54.

TAKEUCHI, H. (1997). Criação de conhecimento na empresa: como as empresas japonesas geram a dinâmica da inovação. Campus, Rio de Janeiro.

TOYAMA, R.; Konno, N. (2000) SECl, Ba and leadership: a unified model of dynamic knowledge creation. Managing Knowledge an Essential Reader.33.5-34.

PAIVA, S. B. (2005). Abordagem Gerencial do Capital Intelectual em uma Organização Baseada em Conhecimento: o caso SEBRAE-PB. UFPB-PPGA, João Pessoa.

SCHREIBER, G.; Akkermans, H.; Anjewierden, A.; De Hoog, R.; Shadbolt, N.; Van De Velde, W.; Wieliga, B.(2000). Knowledge engineering and management. MIT Press, London.

TERRA, J. C. (200I). Gestão do conhecimento: o grande desafio empresarial. Negócio Editora, São Paulo.

ISSN: 07I 8-2724. (http://www.jotmi.org) 